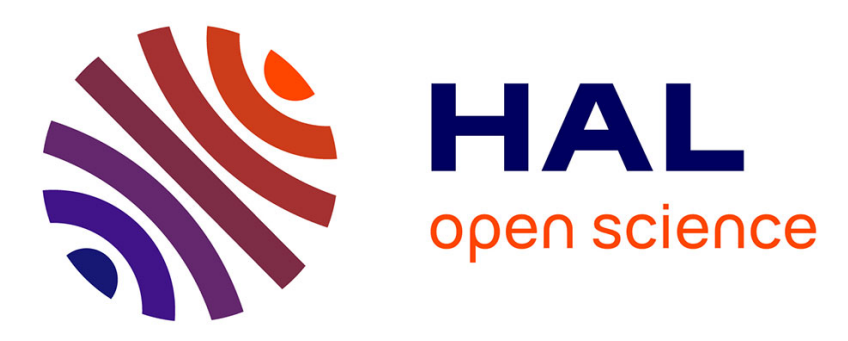

\title{
Gas Phase Synthesis of Protonated Glycine by Chemical Dynamics Simulations
}

\author{
Yannick Jeanvoine, Antonio Largo, William L. Hase, Riccardo Spezia
}

\section{To cite this version:}

Yannick Jeanvoine, Antonio Largo, William L. Hase, Riccardo Spezia. Gas Phase Synthesis of Protonated Glycine by Chemical Dynamics Simulations. Journal of Physical Chemistry A, 2018, 122 (3), pp.869-877. 10.1021/acs.jpca.7b11622 . hal-01688317

\section{HAL Id: hal-01688317 https://hal.sorbonne-universite.fr/hal-01688317}

Submitted on 19 Jan 2018

HAL is a multi-disciplinary open access archive for the deposit and dissemination of scientific research documents, whether they are published or not. The documents may come from teaching and research institutions in France or abroad, or from public or private research centers.
L'archive ouverte pluridisciplinaire HAL, est destinée au dépôt et à la diffusion de documents scientifiques de niveau recherche, publiés ou non, émanant des établissements d'enseignement et de recherche français ou étrangers, des laboratoires publics ou privés. 
On the Gas Phase Synthesis of Protonated Glycine by Chemical Dynamics Simulations

Yannick Jeanvoine, ${ }^{a}$ Antonio Largo, ${ }^{\mathrm{b}}$ William L. Hase ${ }^{\mathrm{c}}$ and Riccardo Spezia ${ }^{\mathrm{a}, \mathrm{d},{ }^{*}}$

${ }^{a}$ LAMBE, Univ Evry, CNRS, CEA, Université Paris-Saclay, 91025, Evry, France

${ }^{\mathrm{b}}$ Computational Chemistry Group, Departamento de Quimica Fisica, Facultad de Ciencias, Universidad de Valladolid, Valladolid, Spain

${ }^{c}$ Department of Chemistry and Biochemistry, Texas Tech University, Lubbock, Texas 794091061, USA

d Sorbonne Universités, UPMC Univ Paris 06, UMR - CNRS 7616, Laboratoire de Chimie Théorique, 75252 Paris, France

* correspondence to: riccardo.spezia@univ-evry.fr, riccardo.spezia@upmc.fr 


\begin{abstract}
In the present work, we investigated the reaction dynamics that will possibly lead to the formation of protonated glycine by an ion-molecule collision. In particular two analogous reactions were studied: $\mathrm{NH}_{3} \mathrm{OH}^{+}+\mathrm{CH}_{3} \mathrm{COOH}$ and $\mathrm{NH}_{2} \mathrm{OH}_{2}^{+}+\mathrm{CH}_{3} \mathrm{COOH}$ that were suggested by previous experiments to be able to form protonated glycine loosing a neutral water molecule. Chemical dynamics simulations show that both reactants can form a molecule with the mass of the protonated glycine but with different structures, if some translational energy is given to the system. The reaction mechanisms for the most relevant product isomers are discussed as well as the role of collision energy in determining reaction products. Finally, in comparing collision dynamics at room and at very low initial internal temperature of the reactants, the same behavior was obtained for forming the protonated glycine isomers products. This supports the use of standard gas phase ion-chemistry set-ups to study collision-induced reactivity as a model for astrophysical cold conditions, when some relative translation energy is given to the system.
\end{abstract}




\section{Introduction}

Ion-molecule reactions are a powerful way to form organic molecules in the gas phase ${ }^{1,2}$ and thus it is often evoked as a possible source for the formation of molecules observed, for example, in space. ${ }^{3,4,5}$ Some years ago, inspired by the suggested observation of glycine in the interstellar medium (ISM), ${ }^{6}$ Bohme and co-workers studied the gas phase synthesis of this amino-acid by ion chemistry techniques, concluding that the reactions

$$
\begin{array}{ll}
\mathrm{NH}_{3} \mathrm{OH}^{+}+\mathrm{CH}_{3} \mathrm{COOH} & \mathbf{1} \\
\mathrm{NH}_{2} \mathrm{OH}_{2}+{ }^{+}+\mathrm{CH} 3 \mathrm{COOH} & \mathbf{2}
\end{array}
$$

are responsible to the formation of protonated glycine and water. ${ }^{7,8}$ Note that it was not possible to determine the protonation site of hydroxylamine, $\mathrm{NH}_{2} \mathrm{OH}$. The $\mathrm{NH}_{3} \mathrm{OH}^{+}$tautomer is more stable than $\mathrm{NH}_{2} \mathrm{OH}_{2}{ }^{+}$but since the protonation was done by collision with $\mathrm{CH}_{5}{ }^{+}$it was not possible to exclude formation of the high-energy tautomer.

Though it was concluded that glycine was not observed in the ISM, after a debated in the astrophysical community, ${ }^{9}, 10,11,12$ the recent mission on the comet $67 \mathrm{P} /$ ChuryumovGerasimenko reports the presence of glycine within other prebiotic molecules. ${ }^{13}$ The possibility of forming it via ion-molecule reaction is still of astrophysical interest and, anyhow, it is an interesting example of gas phase synthesis of a complex organic molecule. Furthermore, experimental and theoretical studies have proposed the formation of glycine in interstellar ices, ${ }^{14}$ or at the radical interface, ${ }^{15}$ via different pathways depending on the composition of the ice. ${ }^{16}$ It was often suggested that UV irradiation is necessary to trigger these reactions. ${ }^{17}$ Note that reactions in the condensed phase can involve more than two reactant molecules, as suggested by Maeda and Ohno in the formation of glycine via the $\mathrm{NH}_{3}$ $+\mathrm{CH}_{2}+\mathrm{CO}_{2}$ reaction. ${ }^{18}$ Here we explore dynamical properties related to possible ionchemistry mechanisms, which are generally restricted to two reactant molecules in ultravacuum, low density, conditions.

The aim of our study is to understand the ion-molecule reactive scattering suggested by reactions 1 and 2. The experiments done by Bohme and co-workers were performed in a room temperature mass spectrometer and the products were first characterized by their mass-overcharge ratio, $\mathrm{m} / \mathrm{z} 76$ corresponding to protonated glycine. Then a fragmentation spectrum at different energies was done for the $\mathrm{m} / \mathrm{z} 76$ formed and compared with a standard of protonated glycine, finding similar behaviors. The way this reaction occurs, however, is still unclear for (at least) three aspects: (i) what is the protonated hydroxylamine tautomer that 
reacts, $\mathrm{NH}_{3} \mathrm{OH}^{+}$or $\mathrm{NH}_{2} \mathrm{OH}_{2}^{+}$? (ii) Does the product observed have the structure of glycine? Note that mass spectra do not provide direct information on the structure. (iii) What is the mechanism of the reaction? Chemical dynamics simulations, modeling explicit ion molecule collisions, provide a possible way to answer these questions. In particular, questions (ii) and (iii) can be answered directly from the outcome of the dynamics, and question (i) indirectly by using as reactants both $\mathrm{NH}_{3} \mathrm{OH}^{+}$and $\mathrm{NH}_{2} \mathrm{OH}_{2}{ }^{+}$ions and see if there is a difference in reactivity.

Recently, we used chemical dynamics simulations to suggest a possible synthetic route for formation of formamide in the interstellar medium ${ }^{19}$ and, nicely, the reaction is very similar to reaction 2, namely $\mathrm{NH}_{2} \mathrm{OH}_{2}{ }^{+}+\mathrm{H}_{2} \mathrm{CO}$. In this case, it was possible to study the reaction dynamics by using MP2/6-31G(d,p) level of theory to obtain the on-the-fly potential energy surface. Reactions $\mathbf{1}$ and $\mathbf{2}$ involve more atoms and for their study MP2 is not computationally feasible. Furthermore, since the system is bigger, the number of trajectories should increase to have statistically representative results and each trajectory should be longer than for the previous study to allow for complex molecular rearrangement. The potential energy surface (PES) proposed by Bohme and co-workers, ${ }^{7}$ was recently revised by Largo and co-workers, ${ }^{20}$ showing that the reaction proceeds via several intermediates and transition states, whose energies are incompatible with the cold conditions of the ISM.

Recently, we have shown that semi-empirical methods can be an alternative way to qualitatively understand reaction dynamics, mainly in the field of unimolecular dissociation, ${ }^{21,22,23,24,25,26}$ and also in the study of ion-molecule collision, where we found that MSINDO semi-empirical Hamiltonian gives results qualitatively in agreement with MP2. ${ }^{19}$ Here we first tested a larger variety of semi-empirical Hamiltonians on the reaction responsible to formamide formation for which we have benchmark MP2 results and thus used the one performing better to study the ion-molecule collisions of reactions $\mathbf{1}$ and $\mathbf{2}$. Present results show that both tautomers are able to react and form ions with the mass of protonated glycine but with different structures.

\section{Methods}

\subsection{Static calculations}

Using quantum chemistry calculations at different levels of theory, the geometry of different structures was optimized for reactions $\mathbf{1}$ and $\mathbf{2}$ and the synthesis of formamide. In particular, we optimized geometries of the reactant molecules for the chemical dynamics simulations and for some possible products. 
For the semi-empirical Hamiltonians benchmark we optimized the precursor molecules, previously identified as possible source of formamide synthesis; i.e. $\mathrm{NH}_{2} \mathrm{OH}_{2}{ }^{+}$and $\mathrm{H}_{2} \mathrm{CO}$. The semi-empirical Hamiltonians used were: AM1, ${ }^{27}$ AM1-D,${ }^{28}$ RM1, ${ }^{29}$ RM1-D, PM3, ${ }^{30}$ PM3-D, ${ }^{28}$ PM6, ${ }^{31}$ PM6-D, MNDO, ${ }^{32}$ MNDO-D and MSINDO. ${ }^{33,34} \mathrm{D}$ stands for dispersion correction as in D1 method of Grimme. ${ }^{35}$ For all calculations the MOPAC-version $5.022 \mathrm{mn}$ software $^{36}$ was used, but for MSINDO calculations for which the corresponding MSINDO code was employed. ${ }^{37}$

We then also optimized the reactants $\mathrm{NH}_{3} \mathrm{OH}^{+}$and $\mathrm{CH}_{3} \mathrm{COOH}$, which may be responsible for glycine synthesis, using the semi-empirical Hamiltonian PM6-D chosen from the above benchmark calculations.

Finally, some selected products were optimized with both PM6-D and MP2/aug-cc-pVTZ. MP2 calculations were done with Gaussian09 package. $^{38}$

\subsection{Chemical dynamics simulations}

Chemical dynamics simulations were performed using the minimum energy structures obtained in section 2.1. Then, the collisional system $\mathrm{A}^{+}+\mathrm{B}$ (where $\mathrm{A}^{+}=\mathrm{NH}_{3} \mathrm{OH}^{+}$or $\mathrm{NH}_{2} \mathrm{OH}_{2}{ }^{+}$and $\mathrm{B}=\mathrm{CH}_{3} \mathrm{COOH}$ ) was set as follows. $\mathrm{A}^{+}$and $\mathrm{B}$ initial coordinates and momenta were obtained from vibrational normal mode sampling around the different minima, in which the vibrational quantum numbers were obtained by Boltzmann sampling of the normal modes. Two temperatures $300 \mathrm{~K}$ and $5 \mathrm{~K}$ were considered, for room and low temperature conditions, respectively. Rotational energy was added giving RT/2 to each principal axis of inertia, with $300 \mathrm{~K}$ and $5 \mathrm{~K}$ considered. These initial conditions were then transformed into Cartesian coordinates and momenta.

Once the reactants internal initial conditions were obtained, conditions for the collisions were set, as reported in details by Hase et al. some years ago, for example. ${ }^{39}$ First, B was randomly placed around $\mathrm{A}^{+}$at a fixed distance, large enough such that they do not interact. Then, we gave a center-of-mass velocity to $\mathrm{A}^{+}$and $\mathrm{B}$ on the same straight line (but opposite orientation in order to make them colliding). These velocities are defined accordingly to the desired collision energy in the center of mass framework. Then the velocity vector of B is shifted by a given value with respect to the center of mass of $\mathrm{A}$, which corresponds to the well-known impact parameter, $b$. Different values of $b$ in the interval $[0-2 \AA]$ were considered. The last value corresponds roughly to the collision radius.

Finally, $\mathrm{A}^{+}$and $\mathrm{B}$ collide with collision energies of 5, 25, 50 and $100 \mathrm{kcal} / \mathrm{mol}$ in the center of mass framework. The direct chemical dynamics simulations were propagated using Newton's 
equation of motion integrated numerically with the velocity Verlet algorithm ${ }^{40}$ with a timestep of $0.1 \mathrm{fs}$, which provides good total energy conservation. The semi-empirical Hamiltonian PM6-D was used to calculate on-the-fly energy and forces for the $\mathrm{NH}_{3} \mathrm{OH}^{+} / \mathrm{NH}_{2} \mathrm{OH}_{2}{ }^{+}+$ $\mathrm{CH}_{3} \mathrm{COOH}$ collisional trajectories.

The simulations for reactions $\mathbf{1}$ and $\mathbf{2}$ consisted of an ensemble of about 5000 trajectory for each $\mathrm{A}^{+}+\mathrm{B}$ collisional system. The trajectories were propagated up to $10 \mathrm{ps}$ or stopped if products are formed and they are far apart of more than $10 \AA$.

For the benchmark $\mathrm{NH}_{2} \mathrm{OH}_{2}{ }^{+}+\mathrm{H}_{2} \mathrm{CO}$ simulations we performed 1000 trajectory for each of different semi-empirical Hamiltonians (see previous section) with collision energy of 25 $\mathrm{kcal} / \mathrm{mol}$ and a random sampling of $b$ in the interval $[0-0.5 \AA]$. These simulations were performed with the same initial conditions of our previous MP2/6-31G(d,p) trajectories, ${ }^{19}$ in order to compare with the MP2/6-31G(d,p) results and to assess the accuracy of semiempirical Hamiltonians for the $\mathrm{NH}_{2} \mathrm{OH}_{2}^{+}+\mathrm{H}_{2} \mathrm{CO} \rightarrow \mathrm{NH}_{2} \mathrm{OCH}_{2}^{+}+\mathrm{H}_{2} \mathrm{O}$ reaction.

The collisional dynamics simulations were performed with the chemical dynamics software VENUS $^{41,42}$ coupled with either MOPAC or MSINDO for the electronic structure calculation.

\subsection{Data analysis}

Trajectories result in thousands of data composed of positions and velocities of all the atoms for each integration time step. To determine if a reaction occurs or not we have analyzed the final products with an automatic tool based on connectivity matrix and graph theory, in a way which is similar to what used in the method developed by Martínez-Núñez to search transition states from chemical dynamics simulations. ${ }^{43}$

The first step is to build the connectivity matrix. In case of reactive collisions, one has to take into account the vibrational amplitude to established a "size" for each atom and set a bond cut-off. Given two atoms, $i$ and $j$, one associates to each atom a radius, $r_{i}$ and $r_{j}$, and the corresponding distance cut-off is $R_{i j}=\left(r_{i}+r_{j}\right) * C$ where $C$ is a parameter which takes into account the vibrational fluctuation of the bonds, being the same for all the $i j$ couples. Then the interatomic distance, $r_{i j}$, is calculated and if $r_{i j}<R_{i j}$ the two atoms are assumed to be linked, otherwise they are not. Atomic radii and $C$ parameters were obtained by a least mean square minimization procedure to reproduce such "elongated" atom-atom distances and they are listed in Table 1.

Then a $N \mathrm{x} N$ distance matrix (where $N$ is equal to the number of atoms) is built, in which an element is set to 1 if the two atoms are bound and 0 if they are not. From this matrix, by using standard graph theory one can recognize automatically the ensemble of atoms that form a 
molecule (a connected graph) and, thus, one can simply detect if a reaction occurs from the connectivity matrix.

\begin{tabular}{|c|c|c|c|c|}
\hline$r_{H}$ & $r_{O}$ & $r_{C}$ & $r_{N}$ & $C$ \\
\hline 0.3720 & 0.7149 & 0.7808 & 0.8022 & 1.2636 \\
\hline$r_{H H}$ & $r_{H O}$ & $r_{H C}$ & $r_{H N}$ & $r_{O O}$ \\
\hline 0.9400 & 1.3733 & 1.4567 & 1.1792 & 1.4230 \\
\hline$r_{O C}$ & $r_{O N}$ & $r_{C C}$ & $r_{C N}$ & $r_{N N}$ \\
\hline 1.4957 & 1.5221 & 1.5617 & 1.5881 & 1.6145 \\
\hline
\end{tabular}

Table 1. Effective atomic radii and parameter $C$ used to automatically identify the products in the collisional trajectories.

\section{Results}

\subsection{Benchmark of semiempirical methods}

In recent work ${ }^{19}$ we studied ion-molecule collisions for formation of protonated formamide in the gas phase at different levels of theory. Stationary point structures and energies were calculated by MP2/aug-cc-pVTZ geometry optimization followed by CCSD(T)/aug-cc-pVQZ electronic energy calculations, MP2/6-31G(d,p) and the semi-empirical MSINDO Hamiltonian. The high level CCSD(T)/aug-cc-pVQZ//MP2/aug-cc-pVTZ calculations were used to benchmark the MP2/6-31G(d,p) and MSINDO calculations of the energetics. The ionmolecule collisions were done by employing MP2/6-31G(d,p) and MSINDO in direct dynamics (in dynamics hundreds of trajectories are required and $\operatorname{CCSD}(\mathrm{T})$ is not affordable). MP2/6-31G(d,p) gives stationary point structures and energies in relatively good agreement with the high level $\operatorname{CCSD}(T)$ calculations, making us confident of the MP2/6-31G(d,p) dynamics.

To study the synthesis of protonated glycine via direct chemical dynamics the MP2 level of theory is computationally too heavy to have a statistically meaningful number of trajectories. Similar to what we observed for fragmentation of amino-acids and peptides, ${ }^{21,23,24}$ semiempirical Hamiltonians may also give a relatively good reactivity picture for ion-molecule collisions, as observed in preliminary calculations for formamide synthesis. ${ }^{19}$ Thus, here semi-empirical Hamiltonians are used to study the formation of amino-acids. The starting 
point was to find the best semi-empirical Hamiltonian and this was done by comparing the simulations using different Hamiltonians with the MP2 simulation results for $\mathrm{NH}_{2} \mathrm{OH}_{2}{ }^{+}+$ $\mathrm{H}_{2} \mathrm{CO}$. For this reaction protonated formamide may be formed in conjunction with neutral water. This reaction is chemically similar to reaction $\mathbf{2}$, in that the protonated product is formed by water loss. The following semi-empirical methods were used in these benchmark test simulations: MSINDO, MNDO, MNDO-D, PM3, PM3-D, PM6, PM6-D, RM1, RM1-D, AM1 and AM1-D.

The products obtained from $\mathrm{NH}_{2} \mathrm{OH}_{2}{ }^{+}+\mathrm{H}_{2} \mathrm{CO}$ simulations with a collision energy of 25 $\mathrm{kcal} / \mathrm{mol}$ are summarized in Figure 1, where the products obtained via the different methods are reported as percentage. A range of different collision dynamics were found: (i) no reaction, with the reactants unchanged; (ii) formation of the most stable $\mathrm{NH}_{3} \mathrm{OH}^{+}$structure through two proton transfers; (iii) proton transfer forming $\mathrm{H}_{2} \mathrm{COH}^{+}$and neutral $\mathrm{NH}_{2} \mathrm{OH}$; (iv) formation of $\mathrm{NH}_{2} \mathrm{OCH}_{2}{ }^{+}+\mathrm{H}_{2} \mathrm{O}$ which, as reported, ${ }^{19}$ can be converted into formamide; and (v) other products not observed in the reference MP2 trajectories.

PM3 provides the worst results, due to the instability of $\mathrm{NH}_{2} \mathrm{OH}_{2}{ }^{+}$, resulting from the too long $\mathrm{N}-\mathrm{O}$ distance $(1.70 \AA$ vs $1.50 \AA$ at MP2/aug-cc-pVTZ level of theory) and leading to the formation of many "other products". Focusing on the production of $\mathrm{NH}_{2} \mathrm{OCH}_{2}{ }^{+}+\mathrm{H}_{2} \mathrm{O}$, which corresponds to the formation of a formamide isomer, ${ }^{19}$ AM1, AM1-D, MNDO and MNDO-D do not show this product, and other methods like PM3-D, RM1 and RM1-D provides a too small amount of it. Finally, PM6, PM6-D and MSINDO provide qualitative similar reactivity, with MSINDO overestimating the amount of $\mathrm{NH}_{2} \mathrm{OCH}_{2}{ }^{+}+\mathrm{H}_{2} \mathrm{O}$ and PM6 and PM6-D overestimating the amount of other products, but providing an amount of $\mathrm{NH}_{2} \mathrm{OCH}_{2}{ }^{+}+\mathrm{H}_{2} \mathrm{O}$ in very good agreement with MP2 results.

The PM6-D method was chosen for the ion/molecule collision dynamics to study $\mathrm{GlyH}^{+}$ synthesis for three reasons: (i) for $\mathrm{NH}_{2} \mathrm{OH}_{2}{ }^{+}+\mathrm{H}_{2} \mathrm{CO}$ it gives a fraction of the water loss pathway similar to the MP2 results and this reaction is similar to the glycine formation reaction we are interested in; (ii) it includes dispersion, which may be important for describing approach of the reactants, and thus the results may be better than PM6; and (iii) PM6-D is included in the MOPAC semi-empirical software, which is interfaced with VENUS in an optimized way such that the calculations are much faster than when using MSINDO. This allows calculation of more and longer trajectories, thus increasing the statistical convergence of the results. 


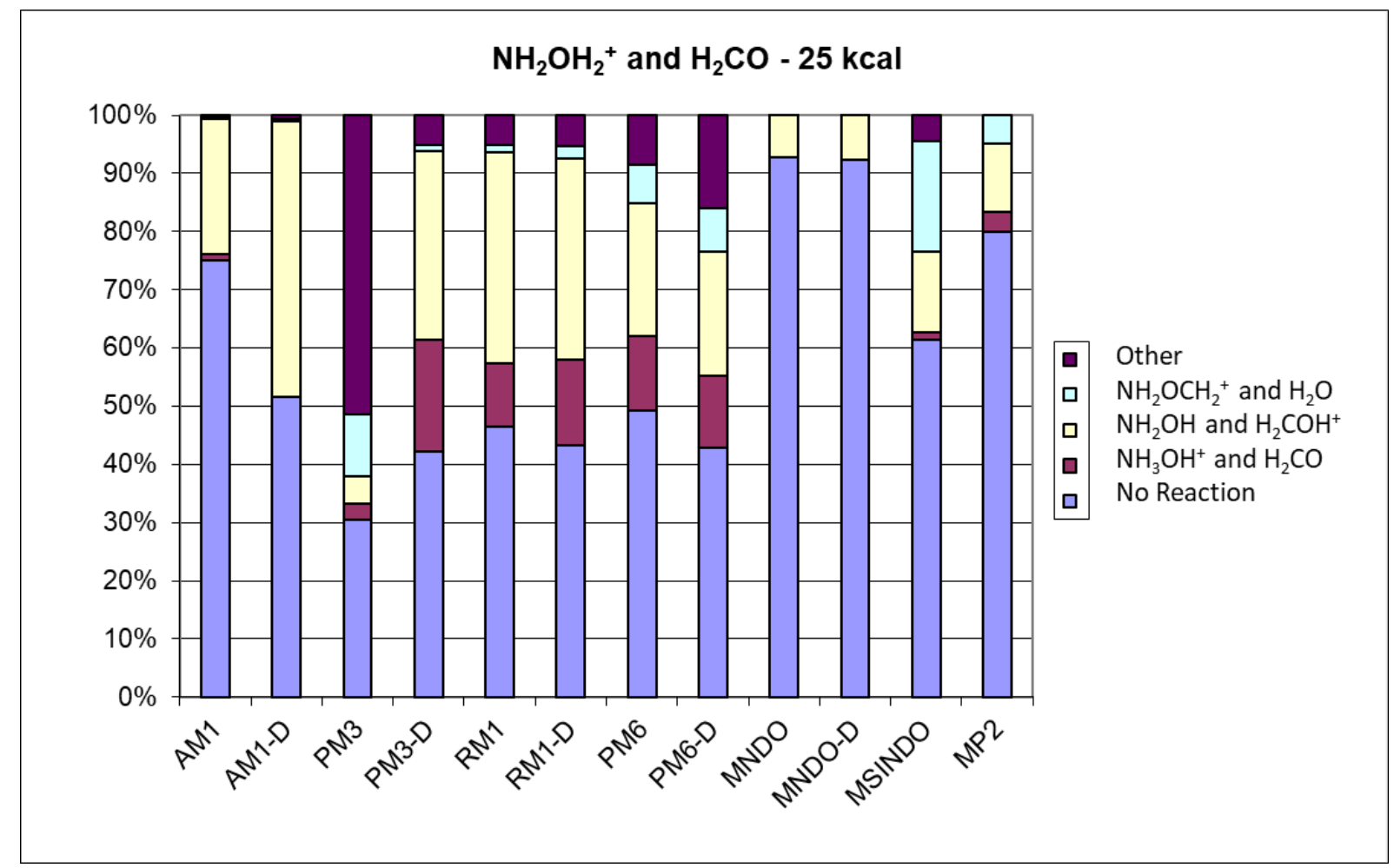

Figure 1. Products of the $\mathrm{NH}_{2} \mathrm{OH}_{2}^{+}+\mathrm{H}_{2} \mathrm{CO}$ reaction as obtained with different semiempirical methods and MP2/6-31G(d,p) trajectories (collision energy $=25 \mathrm{kcal} / \mathrm{mol}$ ).

\subsection{Room temperature collisions}

Given that PM6-D is the best semi-empirical Hamiltonian for reproducing MP2 results for $\mathrm{NH}_{2} \mathrm{OH}_{2}^{+}+\mathrm{H}_{2} \mathrm{CO}$ collisions, it was used to investigate ion-molecule reactions suggested by Bohme and co-workers for forming glycine. ${ }^{7,8}$ As these experiments were performed at room temperature, we mainly investigated collisions with $300 \mathrm{~K}$ reactants. Comparisons with low temperature collisions are shown in section 3.4.

The first reaction investigated is $\mathrm{NH}_{3} \mathrm{OH}^{+}+\mathrm{CH}_{3} \mathrm{COOH}$ (reaction 1), which can lead to protonated glycine by loosing a water molecule. From the PM6-D simulations of this collision, the following reactive pathways were found:

$$
\begin{aligned}
\mathrm{NH}_{3} \mathrm{OH}^{+}+\mathrm{CH}_{3} \mathrm{COOH} & \rightarrow \mathrm{H}_{6} \mathrm{C}_{2} \mathrm{O}_{2} \mathrm{~N}^{+}+\mathrm{H}_{2} \mathrm{O} \\
& \rightarrow \mathrm{NH}_{2} \mathrm{OH}_{2}^{+}+\mathrm{CH}_{3} \mathrm{COOH} \\
& \rightarrow \mathrm{NH}_{2} \mathrm{OH}+\mathrm{H}_{2} \mathrm{O}+\mathrm{CH}_{3} \mathrm{CO}^{+} \\
& \rightarrow \mathrm{CH}_{3} \mathrm{COOH}(\mathrm{H})^{+}+\mathrm{NH}_{2} \mathrm{OH} \\
& \rightarrow\left(\mathrm{NH}_{3} \mathrm{OH}: \mathrm{CH}_{3} \mathrm{COOH}\right)^{+} \\
& \rightarrow \mathrm{NH}_{3} \mathrm{OH}^{+}+\mathrm{H}_{2} \mathrm{O}+\mathrm{CH}_{2} \mathrm{CO}
\end{aligned}
$$


Another pathway is non-reactive scattering, which is in every case the dominant pathway. Thus, it was necessary to largely increase the number of trajectories to have enough reactive events to provide statistically relevant analyses.

The abundances of the different pathways as a function of collision energy and impact parameter are reported in Table S1. From these data the reactive cross section, $\sigma_{i}$, was calculated for each different pathway as:

$$
\sigma_{i}=2 \pi \int_{0}^{b_{\max }} P_{i} b d b
$$

where $P_{i}$ is the probability of the given pathway, $b$ is the impact parameter and $b_{\max }$ the maximum value for the simulation. The reactive cross section gives a direct access to the global reactivity. ${ }^{44}$ In fact the term $2 \pi b d b$ is the area presented to the colliding reactants when $b \in[b, b+d b]$ and this term is multiplied by the reaction probability (here got from simulation results). Note that results for $b=0$ are not included in Eq.1, since the probability that a bimolecular collision occurs with $b=0$ is zero. However, the probability of reaction is maximized for this $b$, and these results may be used to compare with those at low initial temperature (see section 3.4), or for future comparisons with more computationally expensive methods, which are in general performed with very small (or zero) $b$ values in order to maximize the reactive collisions.

Cross sections are reported in Figure 2. The non-reactive pathway is dominant, reflecting the known stability of $\mathrm{NH}_{3} \mathrm{OH}^{+}$and the high reaction barriers also found by both Bohme and coworkers and Largo and co-workers. ${ }^{7,20}$ Reactive cross sections for the other pathways generally increase as the energy increases except pathways 1.1 and 1.5 , which require the reactants to interact for a period of time for reaction to occur. For pathway 1.5 a complex is formed, which is metastable. Since there is no bath to dissipate energy, the complex will return to reactants or form other products on longer time-scales. 


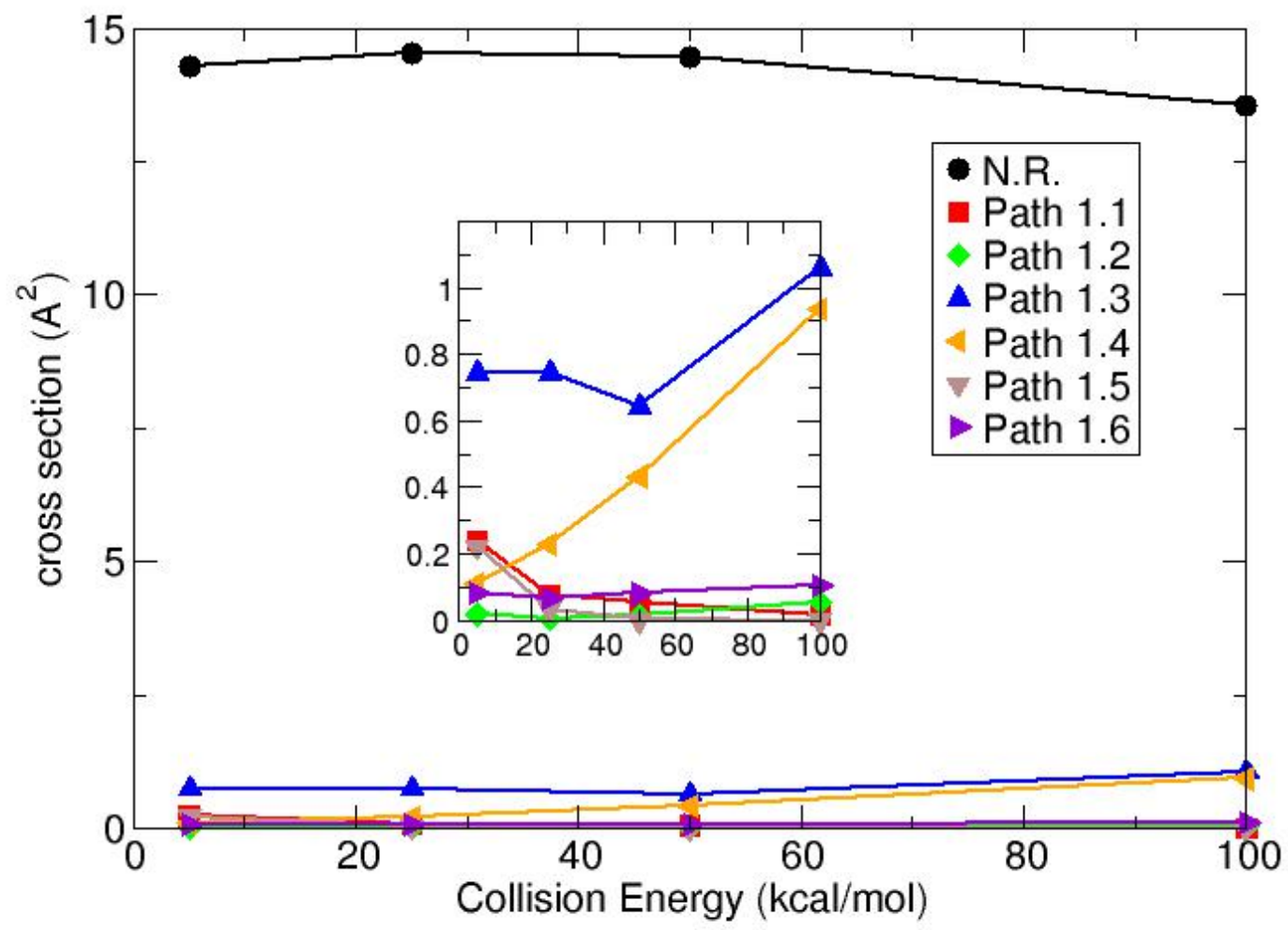

Figure 2. Cross section for the $\mathrm{NH}_{3} \mathrm{OH}^{+}+\mathrm{CH}_{3} \mathrm{COOH}$ collision as a function of the relative collision energy (C.E.). N.R. stays for non-reactive trajectories, while the different pathways correspond to those listed in equations 1.1-1.6. We zoom the low cross section values to better show the cross section evolution of reactive pathways.

Pathway 1.1 would correspond to formation of protonated glycine. However, while the expected water loss was observed and the charged fragments have $m / z 76$ as for glycine, their structures are not that of glycine. In Figure 3 the different isomers for $m / z 76$ are shown, with two, $\mathbf{P 1}$ and $\mathbf{P 2}$, most abundant for $\mathrm{NH}_{3} \mathrm{OH}^{+}+\mathrm{CH}_{3} \mathrm{COOH}$ reaction. Formation of these products is discussed in more detail in section 3.3. It should be recalled that in the experiments of Bohme and co-workers what is detected is the $\mathrm{m} / \mathrm{z}$ value and not structure of the ion. Products of the collision induced dissociation of this ion were then reported as a function of collisional energy and compared with those of commercial protonated glycine. ${ }^{7,8}$ It cannot be excluded that other isomers of protonated glycine are initially formed in these experiments. 
<smiles>CC(=O)[OH+]O</smiles>

P1<smiles>C[C+](O)NO</smiles>

P4

P7<smiles>CC(O)=N[OH2+]</smiles><smiles>CC(=O)O[NH3+]</smiles>

P2<smiles>NC(=O)CO</smiles>

P5<smiles>CN[C+](O)O</smiles><smiles>C[C+](O)ON</smiles>

P3<smiles>CO[C+](N)O</smiles>

P6

Figure 3. Chemical structures of the $m / z 76$ ions obtained from $\mathrm{NH}_{3} \mathrm{OH}^{+} / \mathrm{NH}_{2} \mathrm{OH}_{2}^{+}+$ $\mathrm{CH}_{3} \mathrm{COOH}$ collisions.

The other reactive trajectories show proton transfers, forming protonated acetic acid (1.4) or the high energy protonated hydroxylamine, $\mathrm{NH}_{2} \mathrm{OH}_{2}{ }^{+},(1.2)$, or three products (1.3 and 1.6). Given the reaction barriers for these pathways, their cross sections increase with increase in collision energy and their decreased interaction times with increase in collision energy does not have a negative impact on their cross sections.

Reaction 2 was also investigated, where the reactant is $\mathrm{NH}_{2} \mathrm{OH}_{2}{ }^{+}$, the high energy protonated hydroxylamine structure,. In the experiments of Bohme, protonated hydroxylamine is formed by transferring a proton via the reaction $\mathrm{CH}_{5}{ }^{+}+\mathrm{NH}_{2} \mathrm{OH}$ and they do not know if the low $\left(\mathrm{NH}_{3} \mathrm{OH}^{+}\right)$or high-energy $\left(\mathrm{NH}_{2} \mathrm{OH}_{2}^{+}\right)$tautomer is formed. It cannot be excluded that $\mathrm{NH}_{2} \mathrm{OH}_{2}{ }^{+}$is the structure. This was also suggested in the studies of Bohme and Largo groups who found that the activation energy barrier for the reaction leading to protonated glycine is 
much lower (1.2 and $2.3 \mathrm{kcal} / \mathrm{mol}$ respectively) in the case of $\mathrm{NH}_{2} \mathrm{OH}_{2}{ }^{+}$than for $\mathrm{NH}_{3} \mathrm{OH}^{+}$ reactant. $^{7,20}$

From simulations of $\mathrm{NH}_{2} \mathrm{OH}_{2}^{+}$and $\mathrm{CH}_{3} \mathrm{COOH}$ collisions, the following reactive pathways were observed:

$$
\begin{aligned}
\mathrm{NH}_{2} \mathrm{OH}_{2}^{+}+\mathrm{CH}_{3} \mathrm{COOH} & \rightarrow \mathrm{H}_{6} \mathrm{C}_{2} \mathrm{O}_{2} \mathrm{~N}^{+}+\mathrm{H}_{2} \mathrm{O} \\
& \rightarrow \mathrm{NH}_{3} \mathrm{OH}^{+}+\mathrm{CH}_{3} \mathrm{COOH} \\
& \rightarrow \mathrm{NH}_{2} \mathrm{OH}+\mathrm{H}_{2} \mathrm{O}+\mathrm{CH}_{3} \mathrm{CO}^{+} \\
& \rightarrow \mathrm{CH}_{3} \mathrm{COOH}(\mathrm{H})^{+}+\mathrm{NH}_{2} \mathrm{OH} \\
& \rightarrow\left(\mathrm{NH}_{3} \mathrm{OH}: \mathrm{CH}_{3} \mathrm{COOH}\right)^{+} \\
& \rightarrow \mathrm{NH}_{3} \mathrm{OH}^{+}+\mathrm{H}_{2} \mathrm{O}+\mathrm{CH}_{2} \mathrm{CO}
\end{aligned}
$$

Pathway 2.1 is the equivalent of 1.1, and, as for this pathway, different isomers were obtained for the $\mathrm{H}_{6} \mathrm{C}_{2} \mathrm{O}_{2} \mathrm{~N}^{+}$ion, none of them with the glycine structure. They are shown in Figure 3 . As discussed in more detail in the next session, the three structures, P1, P2 and P3, are the most abundant isomers for this pathway.

In Table S2 the relative abundances of the different pathways are reported, while their cross sections are shown in Figure 4. In contrast to reaction 1, the non-reactive pathway becomes important only at high energy, while at low energies the reactive pathways are highly probable. In particular pathway 2.2, which corresponds to the formation of the most stable $\mathrm{NH}_{3} \mathrm{OH}^{+}$structure, is dominant at low energies. Formation of three products for pathway 2.3 is important, reflecting the instability of $\mathrm{NH}_{2} \mathrm{OH}_{2}^{+}$. Formation of protonated acetic acid (pathway 2.4) is also observed. Pathway 2.1 has a relatively low cross section, somewhat higher than for the $\mathrm{NH}_{3} \mathrm{OH}^{+}$reactant (i.e. pathway 1.1) but the two values are comparable. This suggests that both reactants $\left(\mathrm{NH}_{3} \mathrm{OH}^{+}\right.$and $\left.\mathrm{NH}_{2} \mathrm{OH}_{2}{ }^{+}\right)$can be responsible for formation of the particular ion $m / z 76$, which has the same mass of protonated glycine. We now discuss formation of the three main isomers obtained using both $\mathrm{NH}_{3} \mathrm{OH}^{+}$and $\mathrm{NH}_{2} \mathrm{OH}_{2}{ }^{+}$reactants. 


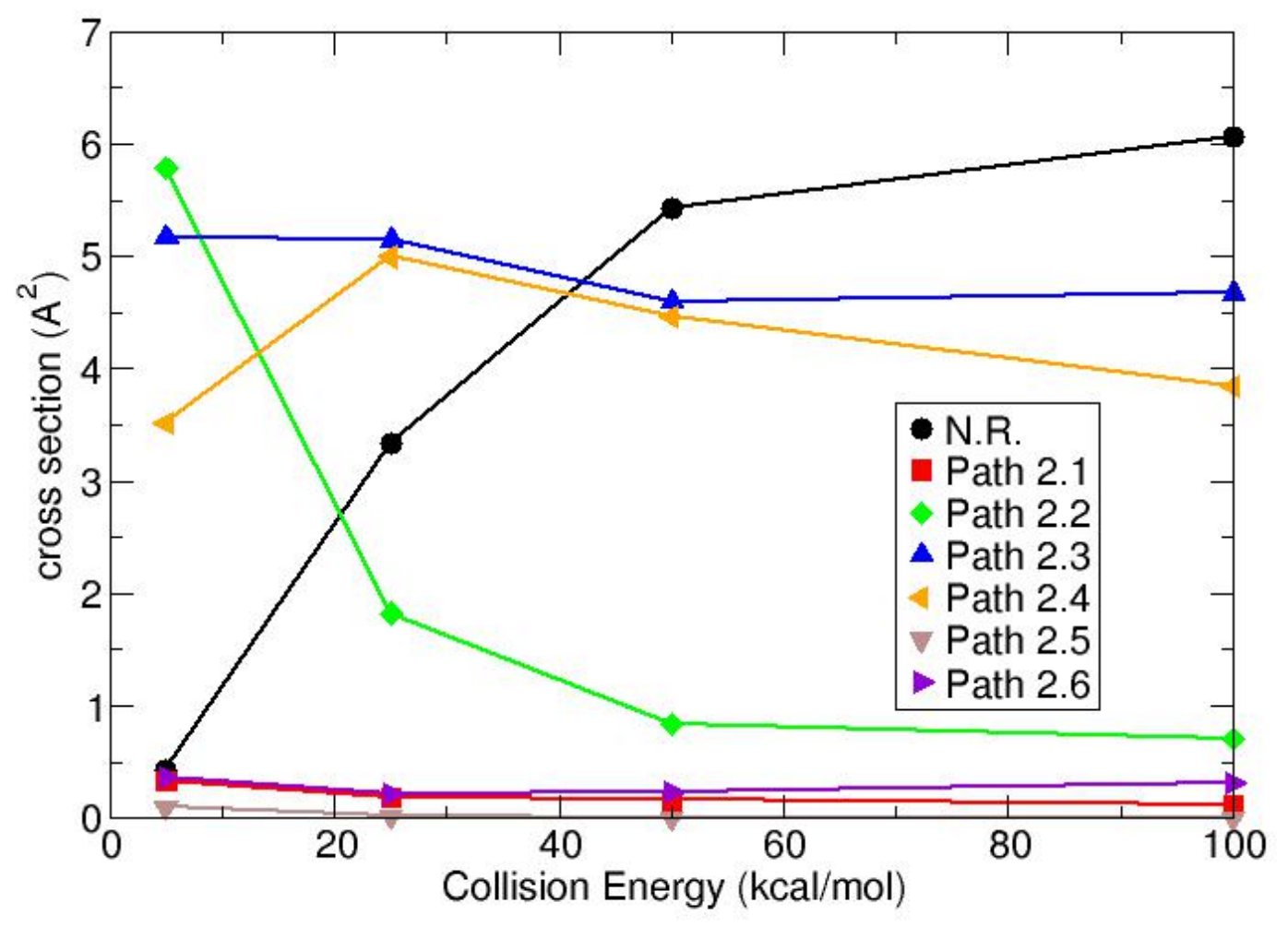

Figure 4. Cross section for the $\mathrm{NH}_{2} \mathrm{OH}_{2}^{+}+\mathrm{CH}_{3} \mathrm{COOH}$ collision as a function of the relative collision energy (C.E.). N.R. stays for non-reactive trajectories, while the different pathways correspond to those listed in equations 2.1-2.6.

\subsection{Mechanisms for the formation of $m / z, 76$ ion}

As previously mentioned, $\mathrm{NH}_{3} \mathrm{OH}^{+} / \mathrm{NH}_{2} \mathrm{OH}_{2}{ }^{+}+\mathrm{CH}_{3} \mathrm{COOH}$ collisions can form a product ion which has the same $m / z 76$ of protonated glycine, but with different structures (see Figure 3). The most abundant ones are P1, P2 and P3, details of their abundance are reported in Tables S3 and S4, while relative cross sections are shown in Figure 5. The cross sections were calculated from the total cross section forming $\mathrm{m} / \mathrm{z} 76$, using $P_{i}$ the probability of forming a given isomer. The P1, P2 and P3 structures were optimized using both PM6-D and MP2/augcc-pVTZ and are reported in Figure 6, while the xyz coordinates are listed in the Supporting Information. Energetics for formation of P1, P2 and P3 are listed in Table 2. 


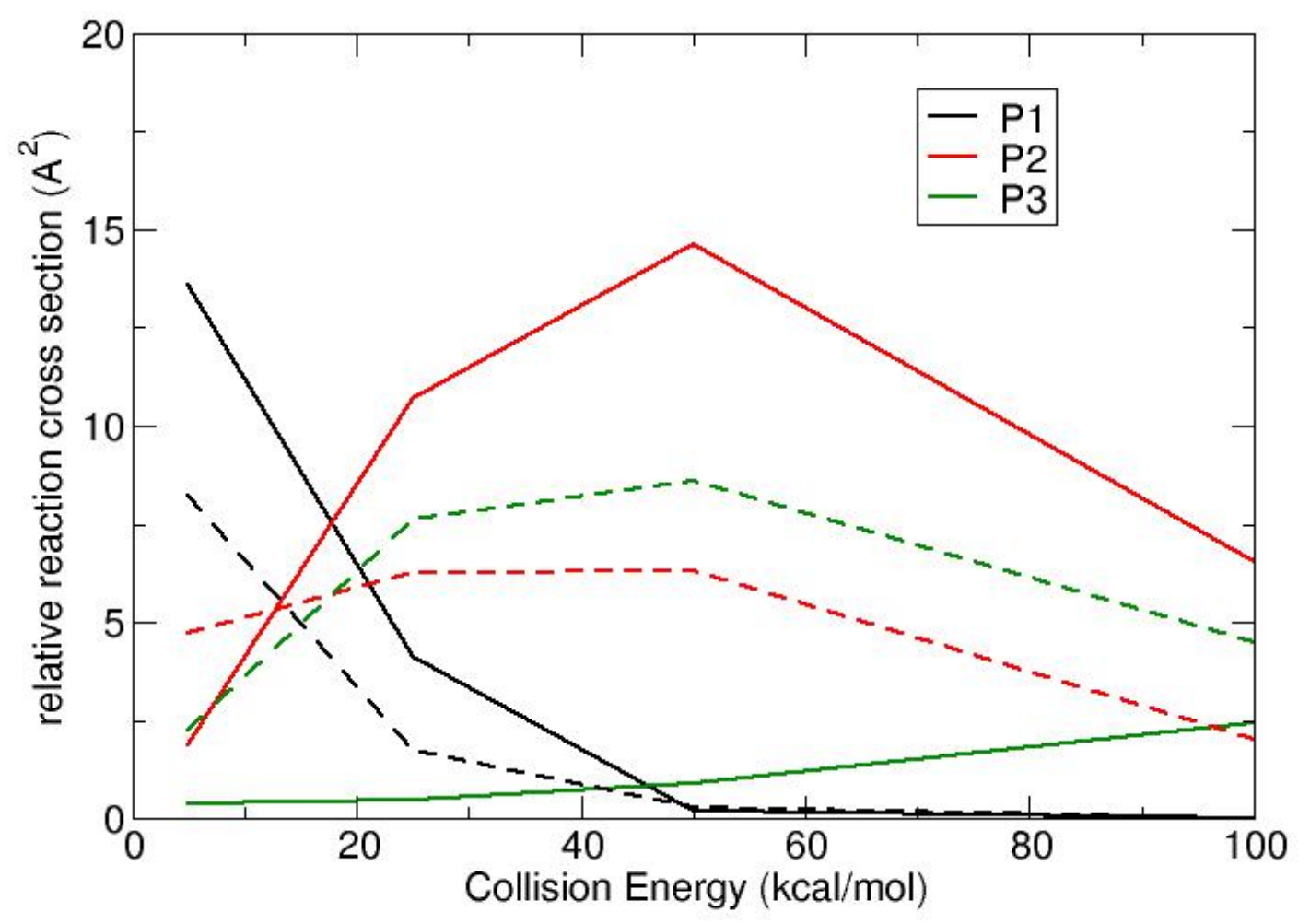

Figure 5. Relative cross sections for P1, $\mathbf{P} 2$ and $\mathbf{P} 3$ formation. $\mathrm{NH}_{3} \mathrm{OH}^{+}+\mathrm{CH}_{3} \mathrm{COOH}$ results are shown as full lines while $\mathrm{NH}_{2} \mathrm{OH}_{2}^{+}+\mathrm{CH}_{3} \mathrm{COOH}$ ones as dashed lines.
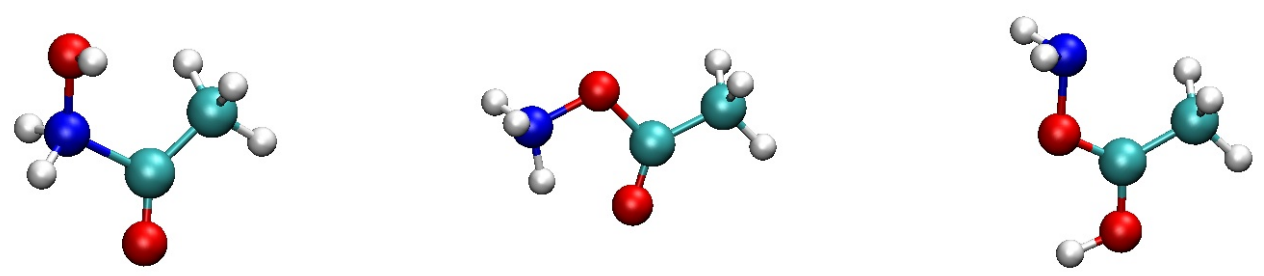

Figure 6. Structures of $\boldsymbol{P 1}$ (left), $\boldsymbol{P 2}$ (middle) and P3 (right) products as optimized at MP2/aug-cc-pVTZ level of theory. 


\begin{tabular}{|l|c|c|c|c|}
\hline Reaction & \multicolumn{2}{|c|}{$\Delta \mathrm{E}(\mathrm{kcal} / \mathrm{mol})$} & \multicolumn{2}{c|}{$\Delta \mathrm{E}+\mathrm{ZPE}(\mathrm{kcal} / \mathrm{mol})$} \\
\hline & PM6-D & MP2 & PM6-D & MP2 \\
\hline $\mathbf{1} \rightarrow \mathbf{P 1}+\mathrm{H}_{2} \mathrm{O}$ & 3.39 & 7.61 & -0.42 & 4.35 \\
\hline $\mathbf{2} \rightarrow \mathbf{P 1}+\mathrm{H}_{2} \mathrm{O}$ & -19.75 & -20.75 & -22.51 & -22.59 \\
\hline $\mathbf{1} \rightarrow \mathbf{P 2}+\mathrm{H}_{2} \mathrm{O}$ & -9.08 & -9.71 & -11.92 & -11.84 \\
\hline $\mathbf{2} \rightarrow \mathbf{P 2}+\mathrm{H}_{2} \mathrm{O}$ & -32.22 & -38.03 & -34.02 & -38.83 \\
\hline $\mathbf{1} \rightarrow \mathbf{P 3}+\mathrm{H}_{2} \mathrm{O}$ & 5.56 & 0.55 & 1.00 & -1.92 \\
\hline $\mathbf{2} \rightarrow \mathbf{P 3}+\mathrm{H}_{2} \mathrm{O}$ & -17.57 & -27.81 & -21.09 & -28.90 \\
\hline
\end{tabular}

Table 2. Energetics of forming $\boldsymbol{P 1}, \boldsymbol{P 2}$ and $\mathbf{P 3}$. MP2 calculations are done with aug-cc-pVTZ basis set. 1 corresponds to $\mathrm{NH}_{3} \mathrm{OH}^{+}+\mathrm{CH}_{3} \mathrm{COOH}$ collision, 2 to $\mathrm{NH}_{2} \mathrm{OH}_{2}{ }^{+}+\mathrm{CH}_{3} \mathrm{COOH}$ collision. P3 isomer was not found stable at MP2/aug-cc-pVTZ level of theory and thus results could not be reported.

$\mathbf{P 1}$ is the most abundant product for both reaction $\mathbf{1}$ and $\mathbf{2}$ at low collision energy, while $\mathbf{P 2}$ and P3 become more important with increased energy, even though P1 is energetically less favored than P2 and P3. Differences between the PM6-D and MP2 energies are small for P1; they give an inverted exo/endo-thermicity for reaction 1, but the difference is small. Remarkably, for P2 the PM6-D and MP2 energies are very similar, while for P3 PM6-D provides less stable product compared to MP2, but the relative energies of the isomers are the same.

By inspecting chemical structure of the product isomers and the mechanisms leading to their formation it is possible to explain the cross section behavior.

For formation of $\mathbf{P 1}$ via reaction $\mathbf{1}$, the reactants form initially a complex, which then reacts via proton transfer from the $\mathrm{NH}_{3}$ group of protonated hydroxylamine to the $\mathrm{OH}$ group of acetic acid. A water molecule is thus formed and it makes a complex with $\mathrm{NH}_{2} \mathrm{OH}$ and $\left(\mathrm{COCH}_{3}\right)^{+}$. This last ion is highly electrophilic such that, when the $\mathrm{NH}_{2}$ group is in the right position, it makes the N-C bond thus forming the $\mathbf{P 1}$ product and the $\mathrm{H}_{2} \mathrm{O}$ molecule released. Snapshots representative to this mechanism are shown in Figure 7a.

Formation of $\mathbf{P 2}$ is slightly different. Immediately after the collision, the $\mathrm{H}$ of the $\mathrm{OH}$ group of $\mathrm{NH}_{3} \mathrm{OH}^{+}$is transferred to the $\mathrm{OH}$ of $\mathrm{CH}_{3} \mathrm{COOH}$, forming as above a complex with a highly reactive $\mathrm{NH}_{3} \mathrm{O}$ group and the same electrophilic carbonyl as the previous mechanism, such that $\mathbf{P 2}$ is formed. Snapshots taken from trajectories leading to $\mathbf{P 2}$ are shown as an example in Figure 7b. This reaction needs energy to remove $\mathrm{H}$ from the $\mathrm{OH}$ group of $\mathrm{NH}_{3} \mathrm{OH}^{+}$while in the previous case the proton transferred is more reactive. Note that the energy needed for the $\mathrm{NH}_{3} \mathrm{OH}^{+} \rightarrow \mathrm{NH}_{3} \mathrm{O}+\mathrm{H}^{+}$reaction is $211.6 \mathrm{kcal} / \mathrm{mol}$ (at MP2/aug-cc-pVTZ level of theory) 
while for $\mathrm{NH}_{3} \mathrm{OH}^{+} \rightarrow \mathrm{NH}_{2} \mathrm{OH}+\mathrm{H}^{+}$is $186.0 \mathrm{kcal} / \mathrm{mol}$. This is why by increasing the collision energy there is an increase in the cross section leading to $\mathbf{P 2}$ and why it is not observed at low energies. At low collision energies there is not enough energy to form $\mathrm{NH}_{3} \mathrm{O}$, which is a crucial intermediate to form $\mathbf{P 2}$.

Formation of $\mathbf{P 1}$ and $\mathbf{P 2}$ via reaction $\mathbf{2}$ occurs in a slightly different way, as obtained from simulations. For P1, there are two main mechanisms: (i) $\mathrm{NH}_{2} \mathrm{OH}_{2}{ }^{+}$gives the excess proton on the oxygen atom to the $\mathrm{OH}$ group of $\mathrm{CH}_{3} \mathrm{COOH}$ forming a water molecule, neutral $\mathrm{NH}_{2} \mathrm{OH}$ and electrophilic $\mathrm{CH}_{3} \mathrm{CO}^{+}$species. This two last molecules are thus ready to react forming $\mathbf{P 1}$ structure (an example is provided in Figure 8a); (ii) after the collision the $\mathrm{NH}_{2} \mathrm{OH}_{2}{ }^{+}$ isomerizes into $\mathrm{NH}_{3} \mathrm{OH}^{+}$and $\mathbf{P 1}$ is formed as for reaction 1. For $\mathbf{P 2}$ formation the main mechanism involves $\mathrm{N}-\mathrm{O}$ bond breaking during the collision, then of neutral $\mathrm{H}_{2} \mathrm{O}$ is lost and $\mathrm{NH}_{2}$ makes a bond with $\mathrm{O}$ atom of $\mathrm{C}=\mathrm{O}$ group leading to $\mathbf{P 3}$, which lately isomerizes to $\mathbf{P 2}$ by proton transfer from $\mathrm{OH}$ to $\mathrm{NH}_{2}$. Characteristic snapshots along a trajectory are shown in Figure 8b. Here a trajectory is shown which consists of the time sequence P3, P2, P3 and then ends as P2, which is the most stable structure. This illustrates the importance of running relatively long simulations. Alternatively, $\mathbf{P 2}$ may be obtained via isomerization of $\mathrm{NH}_{2} \mathrm{OH}_{2}{ }^{+}$ into $\mathrm{NH}_{3} \mathrm{OH}^{+}$and the mechanism is then the same as in a $\mathrm{NH}_{3} \mathrm{OH}^{+}+\mathrm{CH}_{3} \mathrm{COOH}$ collision. Finally, $\mathbf{P 3}$ is an intermediate for the $\mathbf{P 2}$ formation mechanism and thus some reactions stop before $\mathbf{P 3}$ can isomerize into $\mathbf{P 2}$. 


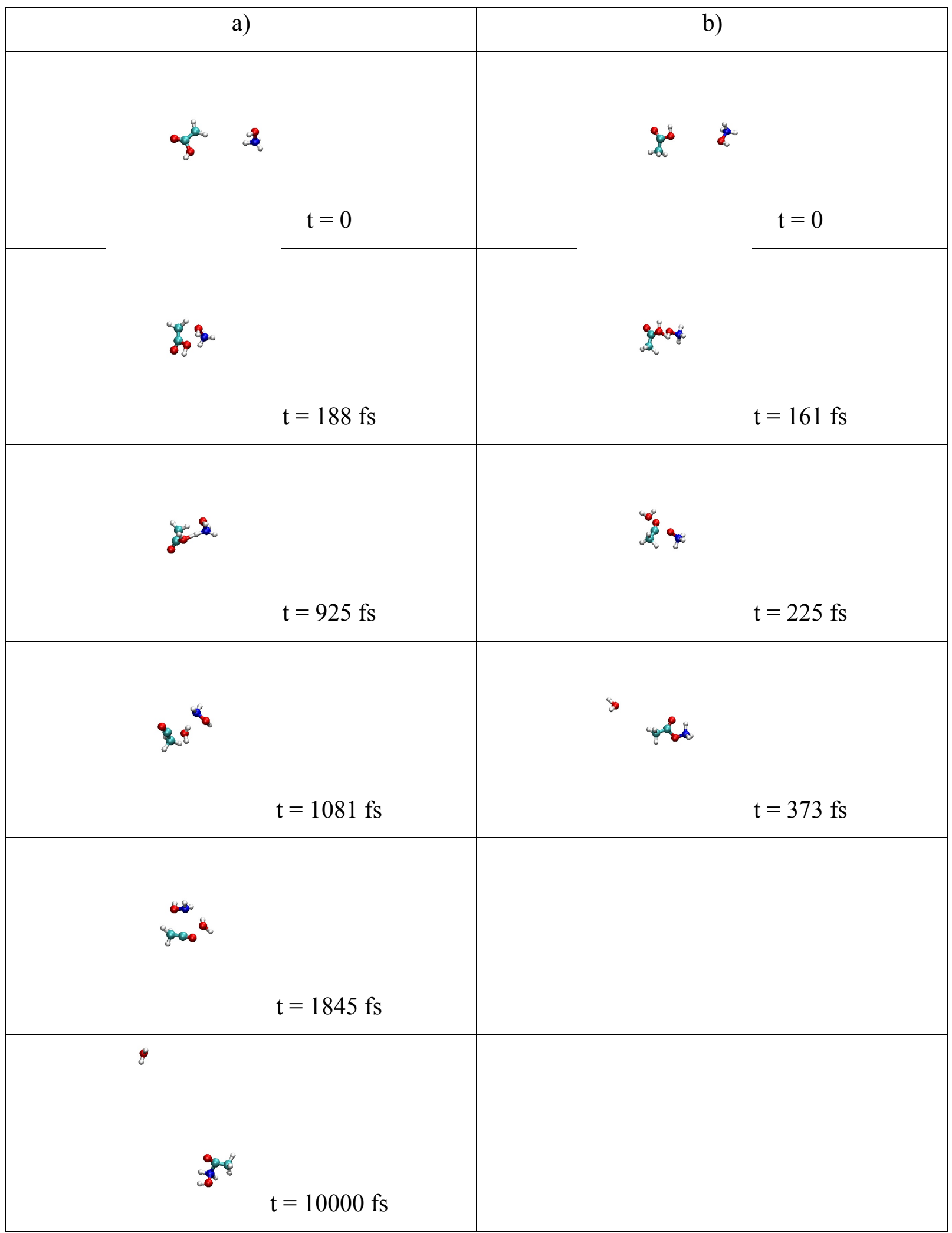

Figure 7. Snapshots showing the key steps for the formation of P1 (panel a) and P2 (panel b) from $\mathrm{NH}_{3} \mathrm{OH}^{+}+\mathrm{CH}_{3} \mathrm{COOH}$ collisions (reaction 1). 


\begin{tabular}{|c|c|c|c|}
\hline \multicolumn{2}{|c|}{ a) } & \multicolumn{2}{|c|}{ b) } \\
\hline 50 & $t=0$ & 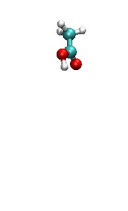 & $\mathrm{t}=0$ \\
\hline 42 & $t=294 \mathrm{fs}$ & 界 & $t=242 \mathrm{fs}$ \\
\hline of & $\mathrm{t}=702 \mathrm{fs}$ & 5 & $\mathrm{t}=509 \mathrm{fs}$ \\
\hline 8 & $\mathrm{t}=4155 \mathrm{fs}$ & 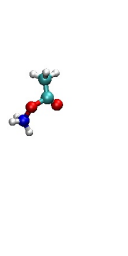 & $\mathrm{t}=572 \mathrm{fs}$ \\
\hline & & dex & $\mathrm{t}=1129 \mathrm{fs}$ \\
\hline & & $x^{2}$ & $\mathrm{t}=3887 \mathrm{fs}$ \\
\hline
\end{tabular}

Figure 8. Snapshots showing the key steps for the formation of $\boldsymbol{P 1}$ (panel a) and $\boldsymbol{P 2}$ (panel b) from $\mathrm{NH}_{2} \mathrm{OH}_{2}^{+}+\mathrm{CH}_{3} \mathrm{COOH}$ collisions (reaction 2). Here we show the mechanisms which are different from the ones obtained from $\mathrm{NH}_{3} \mathrm{OH}^{+}+\mathrm{CH}_{3} \mathrm{COOH}$ collisions (see text for details). 


\subsection{Low temperature results}

Finally, the ion-molecule experiments performed by Bohme and co-workers were done with the aim of modeling reactions pertinent to the interstellar medium. Even if, after their work, the astrophysical community agreed that glycine was not observed in the ISM, the question weather these experimental conditions are a good model for reactions in the ISM is still of interest. In the experiments, the reactants were at room temperature, while in the ISM molecules are very cold. To consider low temperatures, we performed a series of test simulations in which the precursors are very cold $(5 \mathrm{~K})$ and compared with the room temperature results. While the internal temperature is set to $5 \mathrm{~K}$ the collision energy was set to $5 \mathrm{kcal} / \mathrm{mol}$ which corresponds to a very high temperature. The hypothesis behind is that ions can assume a certain amount of translational energy (they can be accelerated, for example, by a magnetic field) even if they are very cold internally. In any case we have chosen the lowest value of collision energy in order to compare with $300 \mathrm{~K}$ simulations at the same value.

The following collisional conditions were considered for the low temperature simulations: (i) $b=0$ to maximize reactivity; (ii) $\mathrm{NH}_{3} \mathrm{OH}^{+}+\mathrm{CH}_{3} \mathrm{COOH}$ collisions, in which the protonated hydroxylamine reactant is at its lowest energy tautomer; and (iii) the lowest value of the collision energy ( $5 \mathrm{kcal} / \mathrm{mol})$. The overall reactivity is $12 \%$, which compare well with the value found for the same conditions of $b$ and collision energy at $300 \mathrm{~K}(14.6 \%)$. As for $300 \mathrm{~K}$, we obtained different proton transfer reactions and, more interestingly, a product composed of an ion with $m / z 76$ and a water molecule. As discussed above, such products do not have the geometry of protonated glycine and they are the P1, P2, P3, P5 and P7 found in the $300 \mathrm{~K}$ simulations and reported in Figure 3. In Figure 9 we compare the probabilities of forming the different isomers at 5 and $300 \mathrm{~K}$ with the same collisional conditions, i.e. collision energy of $5 \mathrm{kcal} / \mathrm{mol}$ and $b=0 . \mathbf{P 1}$ and $\mathbf{P 2}$ are the most abundant isomers for both temperatures and a small number of $\mathbf{P 3}$ and $\mathbf{P 5}$ products were observed at both 5 and 300K. The P7 product was observed only at low temperature, but its abundance is very few (only 2 trajectories), statistically unimportant, and in any case not relevant.

Concluding, it is seen that the vibrational/rotational temperature of the reactants has a very small effect on the reactivity and in particular on the product yield, the product distribution, and abundance of the different $\mathrm{m} / \mathrm{z} 76$ isomers. 


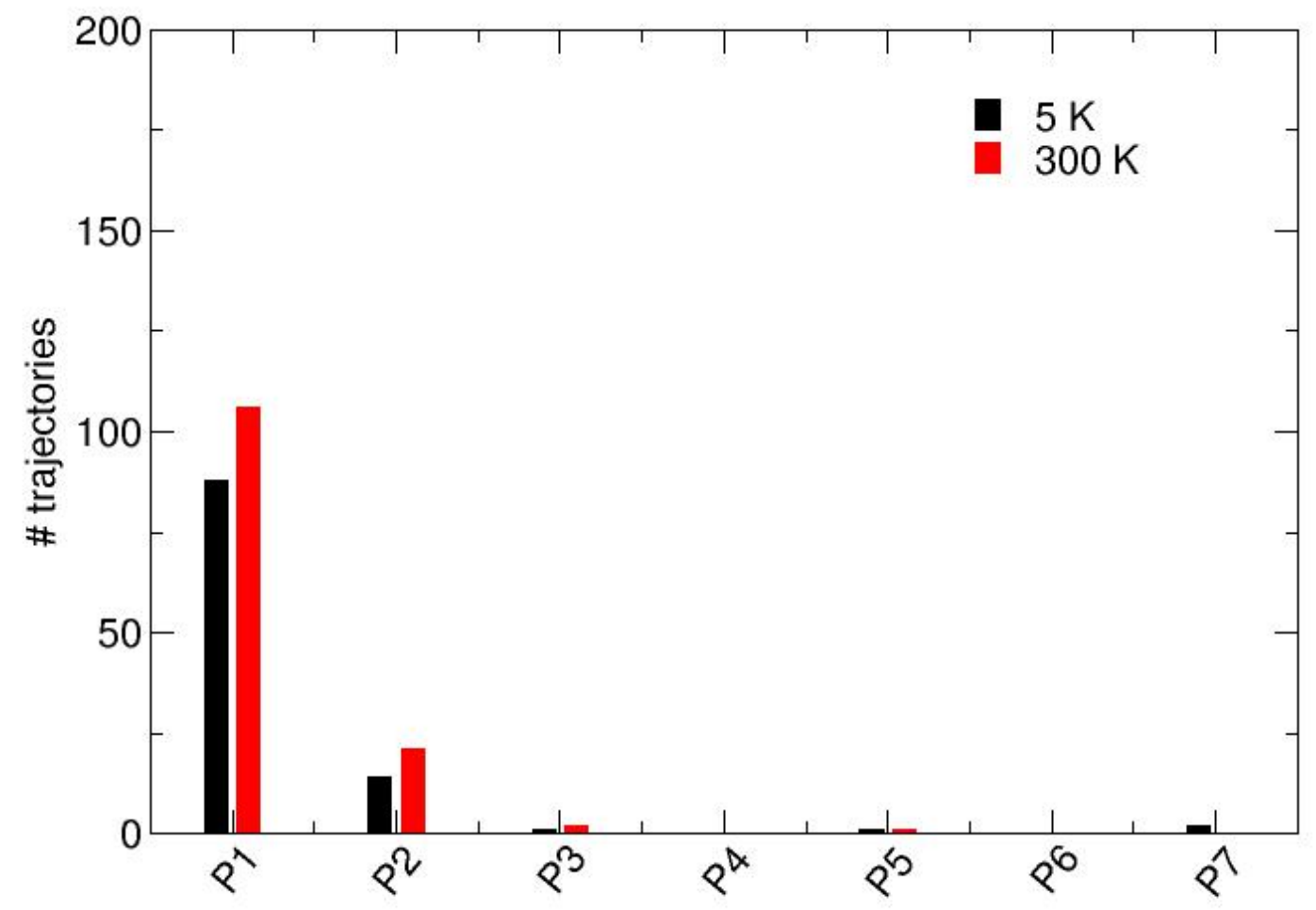

Figure 9. Occurrence of different products with $\mathrm{m} / 2$ from $\mathrm{NH}_{3} \mathrm{OH}^{+}+\mathrm{CH}_{3} \mathrm{COOH}$ reactivity where the initial rovibrational temperature of the reactant is set to 5 and $300 \mathrm{~K}$, respectively. In both cases collision energy is $5 \mathrm{kcal} / \mathrm{mol}$ and $b=0$.

\section{Conclusions}

In the present work, we have investigated the possibility of forming protonated glycine via ion-molecule reactions. Both $\mathrm{NH}_{3} \mathrm{OH}^{+}$and $\mathrm{NH}_{2} \mathrm{OH}_{2}{ }^{+}$tautomers of protonated hydroxylamine are able to react with neutral acetic acid under gas phase conditions, given that some translational energy is provided. Reaction products are found which correspond to those suggested experimentally, i.e. an ion with $\mathrm{m} / z 76$ and neutral water. However, the ion does not have the structure of protonated glycine, but a distribution of isomeric structures all different from glycine. Detailed reaction mechanisms explain why these different isomers are formed. The current simulation results suggest astrophysicists should look for spectroscopic signatures of these glycine isomers in the ISM, eventually.

Finally, we should note that experiments were done at room temperature, in contrast to the low temperatures of astrophysical conditions. For our $\mathrm{NH}_{3} \mathrm{OH}^{+}+\mathrm{CH}_{3} \mathrm{COOH}$ and $\mathrm{NH}_{2} \mathrm{OH}_{2}^{+}$ 
simulations, using quasi-classical trajectories, the vibrational and rotational temperature of the reactants does not have a crucial role in determining the probabilities of formation the protonated glycine isomers is some reactant relative translational energy is present.

\section{Associated Content}

Supporting Information is available: details on probabilities of different pathways; abundance of different isomers of product $\mathrm{m} / \mathrm{z} 76$; xyz coordinates of isomers of protonated glycine $(\mathrm{m} / \mathrm{z}$ 76).

\section{Acknowledgments}

We thank ANR DynBioReact (Grant No. ANR-14-CE06-0029-01), the National Science Foundation under Grant No. CHE-1416428, and the Robert A. Welch Foundation under Grant No. D-0005 for support. Y.J. and R.S. thank CNRS program INFINITI (project ASTROCOL) for partial support. Finally, R.S. thanks Universidad de Valladolid for a visiting professor fellowship.

\section{Graphic TOC}

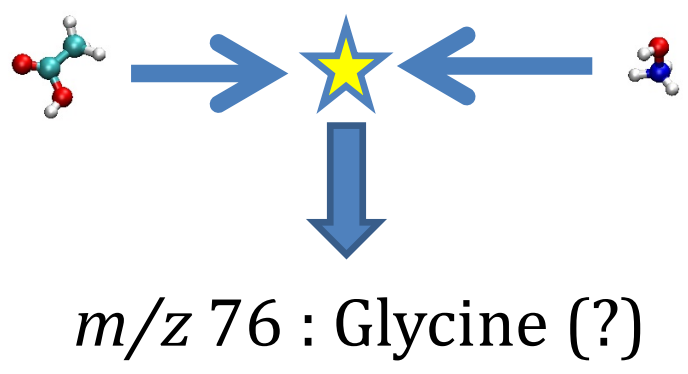

\section{References}

\footnotetext{
${ }^{1}$ Herman, Z.; Futrell, J.H. Dynamics of ion-molecule reactions from beam experiments: A historical survey. Int. J. Mass Spectrom. 2015, 377, 84-92.

${ }^{2}$ Ferguson, E.E. Ion-molecule reactions. Annu. Rev. Phys. Chem. 1975, 26, 17-38.

${ }^{3}$ Larsonn, M.; Geppert, W. D.; Nyman, G. Ion chemistry in space. Rep. Prog. Phys. 2012, 75, 066901.

${ }^{4}$ Petrie, S. ; Bohme, D. K. Ions in space. Mass Spectrom. Rev. 2007, 26, 258-280.

${ }^{5}$ Geppert, W. D. ; Larsson, M. Experimental Investigations into astrophysically relevant ionic Reations. Chem. Rev. 2013, 113, 8872-8905.
} 
${ }^{6}$ Kuan, Y.-J. ; Charnley, S. B. ; Huang, H.-C. ; Tseng, W.-L. ; Kisiel Z. Interstellar glycine. Astrophys. J. 2003, 593, 848-867.

${ }^{7}$ Snow, J. L. ; Orlova, G. ; Blagojevic, V. ; Bohme, D. K. Gas-phase ionic syntheses of amino acids : $\beta$ versus $\alpha . J$. Am. Chem. Soc. 2007, 129, 9910-9917.

${ }^{8}$ Blagojevic, V. ; Petrie, S. ; Bohme, D. K. Gas-phase syntheses for interstellar carboxylic and amino acids. Mon. Not. R. Astron. Soc. 2003, 339, L7-L11.

${ }^{9}$ Snyder, L. E. ; Lovas, F. J. ; Hollis, J. M. ; Friedel, D. N. ; Jewell, P. R. ; Remijan, A. A rigorous attempt to verify interstellar glycine. Astrophys. J. 2005, 619, 914-930.

${ }^{10}$ Cunningham, M. R. ; Jones, P. A. ; Godfrey, P. D. ; Cragg, D. M. ; Bains, I. ; Burton, M. G. ; Calisse, P. ; Crighton, N. H. M. ; Curran, S. J. ; Davis, T. M. ; Dempsey, J. T. ; Fulton, B. ; Hidas, M. G. ; Hill, T. ; Kedziora-Chudczer, L. ; Minier, V. ; Pracy, M. B. ; Purcell, C. ; Shobbrook, J. ; Travouillon, T. A search for propylene oxide and glycine in Sagittarius B2 (LMH) and Orion. Mon. Not. R. Astron. Soc. 2007, 376, 1202-1210.

11 Jones, P. A. ; Cunningham, M. R. ; Godfrey, P. D. ; Cragg, D. M. A Search for biomolecules in Sagittarius B2 (LMH) with the Australia telescope compact array. Mon. Not. R; Astron. Soc. 2007, 374, 579-589.

${ }^{12}$ Hollis, J. M. ; Pedelty, J. A. ; Snyder, L. E. ; Jewell, P. R. ; Lovas, F. J. ; Palmer, P. ; Liu, S.-Y. A sensitive very large array search for small-scale glycine emission toward OMC-1. Astrophys. J. 2003, 588, 353-359.

${ }^{13}$ Altwegg, K. ; Balsiger, H. ; Bar-Nun, A. ; Berthelier, J.-J. ; Bieler, A. ; Bochsler, P. ; Briois, C. ; Calmonte, U. ; Combi, M. R. ; Cottin, H. ; et al. Prebiotic chemicals - amino acid and phosphorus - in the coma of comet 67P/Churyumov-Gerasimenko. Sci. Adv. 2016, 2, e1600285.

${ }^{14}$ Holtom, P. D. ; Bennett, C. J. ; Osamura, Y. ; Mason, N. J. ; Kaiser, R. I. A combined experimental and theoretical study of the formation of the amino acid glycine $\left(\mathrm{NH}_{2} \mathrm{CH}_{2} \mathrm{COOH}\right)$ and its isomer $\left(\mathrm{CH}_{3} \mathrm{NHCOOH}\right)$ in the extraterrestrial ices. Astrophys. $J$. 2005, 626, 940-952.

${ }^{15}$ Rimola, A.; Sodupe, M. ; Ugliengo, P. Computational study of interstellar glycine formation occurring at radical surfaces of water-ice dust particles. Astrophys. J. 2012, 754, 24.

${ }^{16}$ Elsila, J. E. ; Dworkin, J. P. ; Bernstein, M. P. ; Martin, M. P. ; Sandford, S. A. Mechanisms of amino acid formation in interstellar ice analogs. Astrophys. J. 2007, 660, 911-918.

17 Woon, D. E. Pathways to glycine and other amino acids in ultraviolet-irradiated astrophysical ices determined via quantum chemical modeling. Astrophys. J. 2002, 571, L177-L180.

${ }^{18}$ Maeda, S.; Ohno, K. No activation barrier synthetic route of glycine from simple molecules $\left(\mathrm{NH}_{3}, \mathrm{CH}_{2}\right.$, and $\left.\mathrm{CO}_{2}\right)$ via carboxylation of ammonium ylide : a theoretical study by the scaled hypersphere search method. Chem. Phys. Lett. 2004, 398, 240-244.

${ }^{19}$ Spezia, R.; Jeanvoine, Y.; Hase, W.L.; Song, K. ; Largo A. Synthesis of formamide and related organic species in the interstellar medium via chemical dynamics simulations. Astrophys. J. 2016, 826, 107.

${ }^{20}$ Barrientos, C. ; Redondo, P. ; Largo, L. ; Rayon, V. M. ; Largo, A. Gas-phase synthesis of precursors of interstellar glycine : a computational study of the reactions of acetic acid with hydroxylamine and its ionized and protonated derivatives. Astrophys. J. 2012, 748, 99.

${ }^{21}$ Ortiz, D.; Martin-Gago, P.; Riera, A.; Song, K. ; Salpin, J.-Y. ; Spezia, R. Gas-phase collision induced dissociation mechanisms of peptides. Theoretical and experimental study of $\mathrm{N}$-formylalanylamide fragmentation. Int. J. Mass Spectrom. 2013, 335, 33-44.

${ }^{22}$ Rossich Molina, E. ; Ortiz, D. ; Salpin, J.-Y. ; Spezia, R. Elucidating collision induced dissociation products and reaction mechanisms of protonated uracil by coupling chemical 
dynamics simulations with tandem mass spectrometry experiments. J. Mass Spectrom. 2015, 50, 1340-1351.

${ }^{23}$ Spezia, R. ; Martens, J. ; Oomens, J. ; Song, K. Collision-induced dissociation pathways of protonated $\mathrm{Gly}_{2} \mathrm{NH}_{2}$ and $\mathrm{Gly}_{3} \mathrm{NH}_{2}$ in the short time-scale limit by chemical dynamics and ion spectroscopy. Int. J. Mass Spectrom. 2015, 388, 40-52.

${ }^{24}$ Homayoon, Z. ; Pratihar, S. ; Dratz, E. ; Snider, R. ; Spezia, R. ; Barnes, G. ; Macaluso, V. ; Martin-Somer, A. ; Hase, W.L. Model Simulations of the thermal dissociation of the TIK $\left(\mathrm{H}^{+}\right)_{2}$ tripeptide. Mechanisms and kinetic parameters. J. Phys. Chem. A 2016, 120, 82118227.

${ }^{25}$ Rossich Molina, E. ; Eizaguirre, A. ; Haldys, V. ; Urban, D. ; Doisneau, G. ; Bourdreux, Y. ; Beau, J.-M. ; Salpin, J.-Y. ; Spezia, R. Characterization of protonated model disaccharides from tandem mass spectrometry and chemical dynamics simulations. ChemPhysChem 2017, $18,2812-2823$.

${ }^{26}$ Rossich Molina, E. ; Salpin, J.-Y.; Spezia, R. ; Martínez-Núñez, E. On the gas phase fragmentation of protonated uracil: A statistical perspective. Phys. Chem. Chem. Phys. 2016, 18, 14980-14990.

${ }^{27}$ Dewar, M. J. S. ; Zoebisch, E. G. ; Healy, E. F.; Stewart, J. J. P. Development and use of quantum mechanical molecular models. 76. AM1: A new general purpose quantum mechanical molecular model. J. Am. Chem. Soc. 1985, 107, 3902.

${ }^{28}$ McNamara, J. ; Hillier, I. Semi-empirical molecular orbital methods including dispersion corrections for the accurate prediction of the full range of intermolecular interactions in biomolecules. Phys. Chem. Chem. Phys. 2007, 9, 2362-2370.

${ }^{29}$ Rocha, G. B. ; Freire, R. O. ; Simas, A. M. ; Stewart, J. P. P. RM1: A Reparameterization of AM1 for H, C, N, O, P, S, F, Cl, Br, and I. J. Comput. Chem. 2006, 27, 1101-1111.

${ }^{30}$ Stewart, J. J. P. Optimization of parameters for semiempirical methods I. Method. J. Comput. Chem. 1989, 10, 209-220.

${ }^{31}$ Stewart, J. J. P. Optimization of parameters for semiempirical methods. V. Modification of NDDO approximations and application to 70 elements. J. Mol. Model. 2007, 13, 1173-1213.

${ }^{32}$ Dewar, M. J. S. ; Thiel, W. Ground states of molecules. 38. The MNDO method. Approximations and parameters. J. Am. Chem. Soc. 1977, 99, 4899.

33 Ahlswede, B.; Jug, K. Consistent modifications of SINDO1: I. Approximations and parameters. J. Comput. Chem. 1999, 20, 563-571.

${ }^{34}$ Ahlswede, B. ; Jug, K. Consistent modifications of SINDO1: II. Applications to first- and second-row elements. J. Comput. Chem. 1999, 20, 572-578.

${ }^{35}$ Grimme, S. Accurate description of van der Waals complexes by density functional theory including empirical corrections. J. Comp. Chem. 2004, 25, 1463-1473.

${ }^{36}$ Stewart, J. J. P. ; Fiedler, L. J. ; Zheng, J. ; Rossi, I. ; Hu, W.-P. ; Lynch, G. C. ; Liu, Y.-P. ; Zhang, P. ; Chuang, Y.-Y.; Pu, J. et al. MOPAC-version $5.022 \mathrm{mn}$ by based on MOPAC 5.0 by J. J. P. Stewart.

${ }^{37}$ Bredow, T. ; Geudtner, G. ; Jug, K. MSINDO (Version 3.3.1) University of Bonn, 2009.

${ }^{38}$ Frisch, M. J.; Trucks, G. W.; Schlegel, H. B.; Scuseria, G. E.; Robb, M. A.; Cheeseman, J. R.; Scalmani, G.; Barone, V.; Mennucci, B.; Petersson, G. A. et al. Gaussian09, Revision D.01; Gaussian, Inc.: Wallingford, CT, 2010.

${ }^{39}$ Hase, W. L. ; Ludlow, D. M. ; Wolf, R. J. ; Schlick, T. Translational and vibrational energy dependence of the cross section for $\mathrm{H}+\mathrm{C}_{2} \mathrm{H}_{4} \rightarrow \mathrm{C}_{2} \mathrm{H}_{5}{ }^{*}$. J. Phys. Chem. 1981, 85, 958-968.

${ }^{40}$ Verlet, L. Computer "experiments" on classical fluids. I. Thermodynamical Properties of Lennard-Jones Molecules. Phys. Rev. 1967, 159, 98.

${ }^{41} \mathrm{Hu}, \mathrm{X}$; Hase, W. L.; Pirraglia, T. Vectorization of the general Monte Carlo classical trajectory program VENUS. J. Comput. Chem. 1991, 12, 1014-1024. 
${ }^{42}$ Hase, W. L.; Duchovic, R. J.; Hu, X.; Komornicki, A.; Lim, K. F.; Lu, D.-H.; Peslherbe, G. H.; Swamy, K. N.; Linde, S. R. V.; Varandas, A.; et al. VENUS. A general chemical dynamics computer program. QCPE Bull. 1996, 16, 671.

${ }^{43}$ Martínez-Núñez, E. An automated method to find transition states using chemical dynamics simulations. J. Comput. Chem. 2015, 36, 222-234.

${ }^{44}$ Levine R. D. Molecular Reaction Dynamics. Cambridge University Press, Cambridge; 2005. 